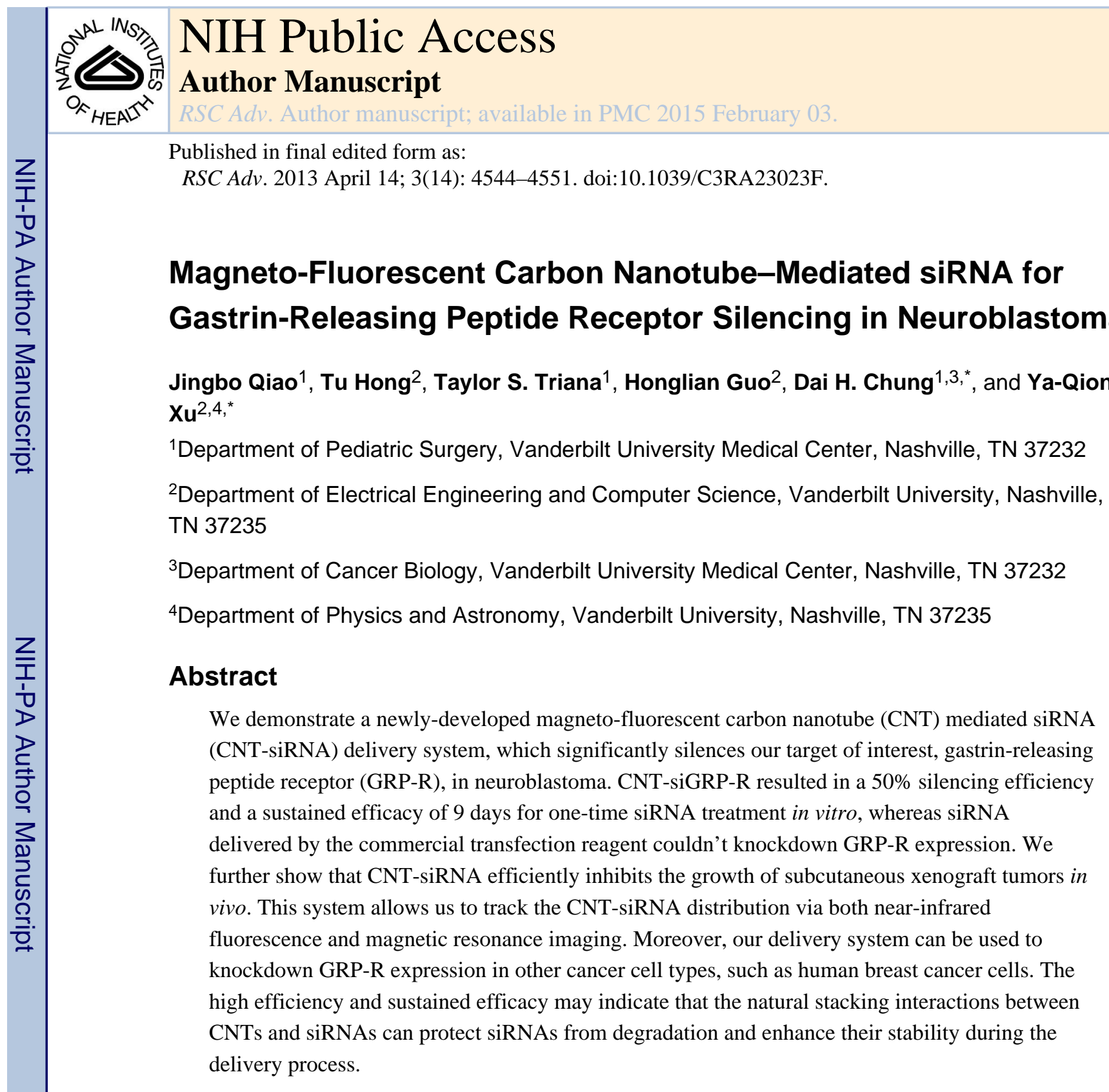

Keywords

CNT; siRNA; Fluorescence; MRI; Neuroblastoma; GRP-R

Neuroblastoma is the most common extra-cranial solid tumors in infants and children, which can arise anywhere along the sympathetic chain and are frequently in the adrenal medulla and paraspinal ganglia. ${ }^{1}$ We have previously demonstrated that small interfering RNA (siRNA)-mediated gastrin-releasing peptide receptor (GRP-R) silencing can significantly suppress tumorigenesis and metastatic potential in murine models of neuroblastoma. ${ }^{2}$ However, the clinical applications of siRNA therapeutics have been impeded by its poor intracellular uptake, instability in vivo, and non-specific immune stimulations. To address these issues, various systems such as lipid-like materials, triblock nanocarriers, modified

\footnotetext{
*To whom correspondence should be addressed, (Y.X.) yaqiong.xu@vanderbilt.edu; (D.H.C.) dai.chung@ vanderbilt.edu.
} 
gold nanoparticles, and quantum dots have been developed for siRNA delivery in vitro and in vivo. ${ }^{3-9}$ Among them, carbon nanotubes (CNTs) have gained significant interest as a promising tool for siRNA delivery due to their capability to cross cell membranes. ${ }^{10,11}$ Moreover, DNA and RNA molecules can naturally wrap around CNTs through the noncovalent $\pi-\pi$ stacking interactions between base pairs and CNT sidewalls. ${ }^{12-15}$ Stable CNT aqueous suspensions formed by coating as-grown CNTs with single-stranded DNA (ssDNA) (Fig. 1A) have been used to deliver siRNA to target specific genes and to retard the growth of established tumor. ${ }^{16,17}$ In order to avoid the interference between the ssDNA used to suspend CNTs and the subsequent siRNA-mediated target silencing, various biocompatible polymers have been used to decorate CNT sidewalls to form stable functionalized-CNT suspensions, which are then conjugated with siRNA oligonucleotides by covalent bonding (Fig. 1B). ${ }^{18-24}$ These covalently-conjugated CNT-siRNA systems have shown the capabilities to knock down specific gene expression, and then to inhibit cell proliferation and tumor progression. ${ }^{10,11,18-25}$ In addition, CNTs have been used as fluorescence imaging agents due to their intrinsic non-bleaching near infrared fluorescence (NIRF) ${ }^{26-33}$ and as magnetic resonance imaging (MRI) contrast agents owing to the magnetic metal catalysts attached to the ends of CNTs. ${ }^{32-38}$ All of these unique intrinsic properties make CNTs ideal candidates for siRNA delivery while their treatment effect can be simultaneously monitored by a variety of imaging methods.

In this study, we developed a magneto-fluorescent CNT-siRNA delivery system for cellular imaging and GRP-R silencing in neuroblastoma, where CNTs were initially suspended by lipo-polyethylene glycol chains (PEG) and then naturally wrapped by siRNA oligonucleotides through the non-covalent $\pi-\pi$ stacking interactions (Fig. 1C). The intrinsic NIRF and MRI of PEG-functionalized-CNTs (PEG-CNTs) allowed us to track the CNT distribution during the siRNA delivery process. We demonstrated that CNT-siRNA delivery was able to significantly silence target GRP-R in neuroblastoma cells with a 50\% silencing efficiency and a sustained efficacy of 9 days for one-time CNT-siRNA treatment, whereas siRNA delivered by the standard transfection method couldn't knockdown GRP-R expression. We further showed that CNT-siRNA efficiently inhibited the growth of subcutaneous xenograft tumors in vivo. Moreover, our CNT-siRNA delivery system can be used for delivery in other types of cancer cells. CNT-siRNA exhibited the capability to reduce GRP-R expression down to $11 \%$ in human breast cancer cells, approximately 5 times more efficient than siRNA mediated by the commercial transfection reagent (Lipofectamine ${ }^{\mathrm{TM}}$ 2000, LIPO). This high efficiency and sustained efficacy may result from the natural stacking interactions between CNTs and siRNAs that can protect siRNAs from degradation and enhance their stability during delivery.

\section{Functionalization of CNTs}

Recently, many surfactants have been used to disperse hydrophobic as-grown CNTs in solution. ${ }^{11,39,40}$ Among them, PEG-CNTs have been used to deliver various biologically active molecules into cells ${ }^{10,11}$ and non-covalently conjugated PEG-CNTs have been tested as a 'least toxic scenario' in mice. ${ }^{41}$ Here, the PEG without an active functional group was used to suspend as-grown HiPco CNTs (single-walled carbon nanotubes with typical length of 100-400 nm and diameter of $1 \mathrm{~nm}$ ) in solution, where a PEG molecule binds strongly to a 
CNT sidewall via non-covalent absorption to form a PEG-CNT. SiRNA oligonucleotides penetrate into the PEG coating and wrap around CNTs through the non-covalent $\pi-\pi$ stacking interactions ${ }^{12-15}$ between base pairs and CNT sidewalls (Fig. 1C).

\section{CNTs for dual-modality imaging of neuroblastoma cells}

In order to evaluate the efficacy of treatment and to improve the pharmacokinetic profile of a drug, it is important for a drug-carrier to be detected by using a variety of imaging methodologies. In this study, we performed MRI of PEG-CNTs and visualized the CNT/ CNT-siRNA distribution in tumor cells via both NIRF and MRI. As-produced CNTs possess metal catalyst nanoparticles at their ends, which can reduce the spin-spin relaxation time of water protons nearby and make CNTs inherent $T_{2}$-weighted MRI contrast agents. The $T_{2^{-}}$ weighted MRI $T_{2}$ maps with various PEG-CNT concentrations are illustrated in Figure 2A. The presence of PEG-CNTs had a significant effect on the $T_{2}$ relaxation time, as commonly observed with iron-based MRI contrast agents. The concentration of iron nanoparticles that attach to the ends of PEG-CNTs was approximately $10 \mathrm{wt} \%$ through the inductively coupled plasma optical emission spectrometry (ICP-OES) measurements. The $T_{2}$-relaxitivity in terms of iron was about $60 \mathrm{~s}^{-1} /(\mathrm{mM} / \mathrm{l})$, which is comparable to that of the commercial MRI contrast agent Ferumoxtran-10 $\left(r_{2}=65 \mathrm{~s}^{-1} /(\mathrm{mM} / \mathrm{l})\right)$. To examine the effectiveness of cellular imaging by using CNTs as an MRI contrast agent, we transfected human neuroblastoma BE(2)-C cells with CNT-siGRP-R. Cells were trypsinized and resuspended into $0.4 \%$ agarose gels at 48 hours post-transfection. As shown in Figure 2B, the samples were prepared with $\mathrm{BE}(2)-\mathrm{C}$ cells that were treated with CNT-siRNA (Fig. 2B, left) and PBS (Fig. 2B, right), respectively. The $T_{2}$ relaxation times of cells containing CNTs (236.6 $0.8 \mathrm{~ms}$ ) were lower than those without CNT-siRNA treatments (245.9 $1.4 \mathrm{~ms}$ ). This indicates that the accumulation and distribution of CNTs can be simultaneously tracked through MRI during the siRNA delivery process.

To demonstrate the feasibility of tracking the CNT distribution via NIRF imaging during delivery, BE(2)-C cells were transfected with CNT-siGRP-R, and resuspended in $0.4 \%$ agarose gels at 48 hours post-transfection. The cell imaging was then carried out in the range of 1150-1700 nm by employing the intrinsic NIRF of CNTs. Figure $2 \mathrm{C}$ shows false-color coded fluorescence images of the cells, obtained by stacking a z-series of images with $10 \mathrm{~s}$ exposure time each and overlaid by the corresponding optical cell images. This image clearly showed that CNT-siGRP-R have been efficiently delivered into the cells. Our experimental results indicate that both intrinsic NIRF and MRI of CNTs in our delivery system can be used to track the distribution of drug carriers (CNTs) and to estimate the delivery efficiency.

\section{CNT-siRNA silence target gene in neuroblastoma in vitro and in vivo}

After validating that CNT-siRNA could be visualized in cells during delivery via both NIRF and MRI, we examined the drug delivery efficiency of CNT-siRNA in human neuroblastoma $\mathrm{BE}(2)-\mathrm{C}$ cells. We transfected $\mathrm{BE}(2)-\mathrm{C}$ cells with LIPO mediated siCON (LIPO-siCON), LIPO-siGRP-R, CNT-siCON, CNT-siGRP-R, naked-siCON, and nakedsiGRP-R, respectively. Protein samples were collected from whole cell lysates that were 
collected at 2 and 9 days post-transfection, respectively, and were analyzed with Western blotting. As shown in Figure 3A, CNT-siGRP-R significantly downregulated GRP-R expression 2 days after transfection, whereas both naked-siGRP-R and commercial transfection reagent LIPO-siGRP-R did not knockdown GRP-R expression. Moreover, the GRP-R silencing efficiency mediated by CNT-siRNA was persistently high at 9 days posttransfection, when most siRNA delivery systems cannot silence target genes for that duration due to the instability of siRNA. The sustained efficacy for one-time treatment is critical for drug delivery in clinical applications, since high efficacy and low frequency treatments can reduce the likelihood of drug toxicity in humans.

To evaluate the efficacy of GRP-R silencing mediated by CNT-siRNA in vivo, we performed CNT-siRNA delivery locally into subcutaneous tumors, which were established with luciferase expressing neuroblastoma $\mathrm{BE}(2)-\mathrm{C}$ cells in athymic nude mice as described previously. ${ }^{2}$ CNT-siCON and CNT-siGRP-R that were prepared as described in Methods were injected into tumors directly. The effects of these drugs on downregulation of GRP-R and inhibition of tumor growth were examined. In vivo bioluminescent imaging was performed as previously described. ${ }^{42}$ The substrate luciferin was injected into the intraperitoneal cavity at a dosage of $150 \mathrm{mg} / \mathrm{kg}$ body weight ( $30 \mathrm{mg} / \mathrm{ml}$ luciferin) approximately $5 \mathrm{~min}$ before imaging. Mice were imaged before, 5 and 27 days after a single administration of CNT-siRNA. Injection of these two siRNA drugs produced significant effects on the tumor sizes in vivo (Fig. 3B, C). CNT-siGRP-R efficiently decreased the tumor size 5 days post injection and significantly inhibit the tumor growth 27 days post injection as compared to controls treated with CNT-siCON. To validate whether the GRP-R expression was affected in the tumors by CNT-siGRP-R treatment, immunohistochemistry (IHC) was performed. The expression of target GRP-R protein levels were significantly decreased in CNT-siGRP-R treated tumors (Fig. 3E) when compared to CNT-siCON controls (Fig. 3D), which was consistent with our in vitro results. Moreover, we found that cells in CNT-siGRP-R treated tumors appeared to lose cell-cell adhesion, and more differentiated on morphologic observation (Fig. 3G). Additionally, paraffin embedded sections were stained with anti-human phosphor-Histone H3 (Ser10) antibody and followed by Alexa Fluor 568 Dye. DAPI (4',6-Diamidino-2-Phenylindole, Dihydrochloride) was used for staining nucleus. Phosphor-Histone H3 (Ser10) is a cell mitosis marker, which is tightly correlated with chromosome condensation during both mitosis and meiosis. ${ }^{43-45}$ As shown in Figure 3H and 3I, there were 70\% less mitotic cells in the CNT-siGRP-R treated tumors than those in the CNT-siCON treated one. (Quantification of mitotic human neuroblastoma cells was counted from different fields in tumor sections.) It is obvious that CNT-siGRP-R treatments significantly reduced tumor cell proliferation and thus inhibited tumor growth. Our results indicate that CNT-siRNA mediated GRP-R targeted therapy may be an advantageous strategy for in vivo inhibition of GRP-R-expressing tumors.

\section{Delivery efficiency in other types of cancer cells}

In addition to neuroblastoma, GRP-R is highly expressed in other neuroendocrine tumors, including breast cancer. ${ }^{46}$ Therefore, we wanted to investigate the delivery efficiency of CNT-siRNA in other types of cancer cells. Using human breast cancer MDA-MB-231 cells, we found that GRP-R expression was significantly knocked down to $11 \%$ at 96 hours post- 
transfection by CNT-siGRP-R (Fig. 4), which was significantly more effective than GRP-R silencing by LIPO-siGRP-R (55\%). In addition, we found that CNT-siGRP-R could efficiently downregulate AKT2, which is the downstream target of GRP-R correlating with chemoresistance. ${ }^{47}$ These results indicate that the downstream signaling pathway of GRP/ GRP-R can be blocked by CNT-siGRP-R. This observation further corroborates that CNTsiRNA delivery is universally relevant for various cancer cell types. The sustained efficacy and high delivery efficiency of CNT-siRNA make it a promising delivery system for clinical applications.

The key challenges for GRP-R mediated siRNA therapy in neuroblastoma are the delivery efficacy $^{48}$ and simultaneous evaluation of the treatment effect. It is desirable to develop a therapeutic strategy to stabilize siRNA, to deliver siRNA into cells, to silence the target oncogene, to inhibit tumor growth and metastasis, and to detect the biodistribution of siRNA through the intrinsic properties of drug-carriers. In the present study, we developed a magneto-fluorescent CNT-siRNA delivery system for cellular imaging and GRP-R silencing in neuroblastoma. In our novel system, CNTs were initially suspended by PEG to improve their cytocompatibility and bioavailability, and then naturally wrapped with siRNA oligonucleotides through the non-covalent $\pi-\pi$ stacking interactions to protect siRNAs from degradation. We visualized the distribution of CNT/CNT-siRNA via both intrinsic NIRF and MRI of CNTs during CNT-siRNA delivery. CNT-siRNA delivery was able to significantly silence target protein, GRP-R, in neuroblastoma with high delivery efficiency and sustained efficacy of 9 days, whereas siRNA delivered by the standard delivery method couldn't knockdown GRP-R expression. To our best knowledge, the sustained efficacy of 9 days is the longest record for one-time siRNA treatment on cells, which may be particularly important for future clinical applications of siRNA since high efficacy and low frequency treatments can potentially reduce drug toxicity in patients. We further showed that CNTsiRNA can efficiently inhibit the growth of mouse subcutaneous xenograft tumors in vivo. Aside from neuroblastoma, CNT-siRNA was also able to reduce GRP-R expression in human breast cancer cells with a reduction rate 5 times more than siRNA mediated by the commercial transfection reagent LIPO. This high efficiency and sustained efficacy of CNTsiRNA may result from the natural stacking interactions between CNTs and siRNAs that can protect siRNAs from degradation and enhance their stability during delivery.

\section{METHODS}

\section{Preparation of functionalized-CNTs}

CNTs were produced by the high-pressure $\mathrm{CO}$ (HiPco) process at Rice University. PEG (1,2-distearoyl-sn-glycero-3-phosphoethanolamine- $\mathrm{N}$-[methoxy (polyethylene glycol)-5000]) was purchased from Avanti Polar Lipids Inc. (Alabaster, AL). CNTs were functionalized with PEGs by the following methods. Hydrophobic CNTs were first dispersed in the $0.1 \mathrm{wt} \%$ PEG water solution and sonicated for $2 \mathrm{~h}$ in an ice water bath sonicator. Then, the uniform CNT suspension was centrifuged with Beckman SW55Ti swing bucket rotor at 133,000 $\mathrm{g}$ and room temperature for $4 \mathrm{~h}$. The upper $80 \%$ of supernatant was carefully decanted, leaving individual PEG-CNTs with a typical mass concentration of $20-30 \mathrm{mg} / \mathrm{L}$. The CNT solution was concentrated to $40 \mathrm{mg} / \mathrm{L}$ via 
centrifugal filter devices at $4,000 \mathrm{~g}$ and $4^{\circ} \mathrm{C}$ for $10 \mathrm{~min}$. The final concentration of the CNT solution was measured by UV-VIS-NIR spectrometer with a weight extinction coefficient of $0.0465 \mathrm{~L} \mathrm{mg}^{-1} \mathrm{~cm}^{-1}$ at $808 \mathrm{~nm}^{11}$. The extra PEG in the CNT solution was removed by water washing through centrifugal filter devices at $4,000 \mathrm{~g}$ and $4^{\circ} \mathrm{C}$ for $10 \mathrm{~min}$; this process was repeated a few times, PEG-CNTs were resuspended in PBS buffer. PEG-CNTs are ready to be wrapped with siRNA through non-covalent stacking interactions.

\section{CNT-siRNA preparation}

SiRNA was synthesized by Thermo Scientific (Dharmacon). The siRNA targeting GRP-R (NM_005314) sequence (siGRP-R): sense: 5'-Thiol-

UAACGUGUGCUCCAGUGGAdTdT-3'; antisense 3'dTdTAUUGCACACGAGGUCACCU-5' ${ }^{\prime}$. Control siRNA targeting Luciferase (siCON): sense: 5'-Thiol-CUUACGCUGAGUACUUCGAdTdT-3'; antisense: 3'dTdTGAAUGCGACUCAUGAAGCU-5' ${ }^{\prime}$. The siRNA solution was prepared by dissolving siRNA in RNase-free water to a final concentration of $100 \mu \mathrm{M}$ for storage. $15 \mu \mathrm{l}$ of $100 \mu \mathrm{M}$ siRNA was added to the PEG-CNT solution to reach a siRNA concentration of $1.7 \mu \mathrm{M}$ in PBS and incubated at $4^{\circ} \mathrm{C}$ for $24 \mathrm{~h}$. The final CNT and siRNA concentrations were approximately $20 \mathrm{mg} / \mathrm{L}$ and $1.7 \mu \mathrm{M}$, respectively. The CNT-siRNA solution was ready for cell transfection.

\section{Cell culture and transfections}

Human neuroblastoma BE(2)-C and breast cancer MDA-MB-231 cell lines were purchased from American Type Culture Collection (Manassas, VA). Cells were cultured in RPMI 1640 medium with L-glutamine (Cellgro Mediatech, Inc. Herndon, VA) supplemented with 10\% fetal bovine serum (FBS, Sigma). Cells were maintained at $37{ }^{\circ} \mathrm{C}$ in a humidified atmosphere of $95 \%$ air and $5 \% \mathrm{CO}_{2}$. For transfection, cells were plated in 6-well plates in $1.5 \mathrm{ml}$ medium overnight and reached $70 \%$ confluence. $0.5 \mathrm{ml}$ of CNT-siRNA solution was then added into cell cultures, in which the final concentrations of CNT and siRNA were 5 $\mathrm{mg} / \mathrm{L}$ and $0.425 \mu \mathrm{M}$, respectively. The cells were incubated for various indicated time points, and then collected for target silencing measurements using Western blot analysis.

\section{Cell preparation for NIRF and MRI}

Cells with or without the CNT-siRNA treatments were trypsinized and washed with culture medium via centrifugation at $200 \mathrm{~g}$ and room temperature for $5 \mathrm{~min}$ and resuspended at the concentration of $2 \times 10^{6}$ cells $/ \mathrm{ml}$ in RPMI 1640 medium without phenol red. The cell solution was mixed with equal volume of $0.8 \%$ agarose gels from Cambrex Bio Science Rockland, Inc. (Rockland, ME) to form final semi-solid cell solution at the concentration of $1 \times 10^{6} \mathrm{cells} / \mathrm{ml}$ in $0.4 \%$ agarose gels. For NIRF imaging, the cell solution was spread on the glass slide. For MRI, the cell solution was added into 96-well plates.

\section{NIRF imaging of CNT-siRNA treated cells}

A $70 \mathrm{~mW} / 785 \mathrm{~nm}$ laser beam (CrystaLaser) was focused on the sample. The emission light was collected by an IR-enhanced 60X water immersion objective (Olympus), filtered by a $950 \mathrm{~nm}$ long pass filter (Thorlabs), and detected by a liquid nitrogen cooling $320 \mathrm{X} 256$ 
pixel InGaAs array detector (2D-OMA V; Princeton Instruments) with an exposure time of $10 \mathrm{~s}$. The final fluorescence cellular images were obtained by adding 5 images taken near the vertical center of the cell.

\section{MRI of CNTs and CNT-siRNA treated cells}

MRI was studied with a 4.7 T 31-cm bore Varian Direct Drive scanner at Vanderbilt University Institute of Imaging Science, which is a fully broad-banded imaging/ spectroscopy system equipped with actively shielded gradients $(40 \mathrm{G} / \mathrm{cm}$, rise times full amplitude of $130 \mu \mathrm{s}$ ), two independent transmit channels and one independent receive channel. For MRI of CNTs, $T_{2}$ signal decay was measured using a Carr-Purcell-MeiboomGill (CPMG) spin-echo pulse sequence with $\mathrm{N}=16$ echoes with 8 millisecond echo spacing. The signal from each voxel at the 16 imaging time points was fit to a monoexponential

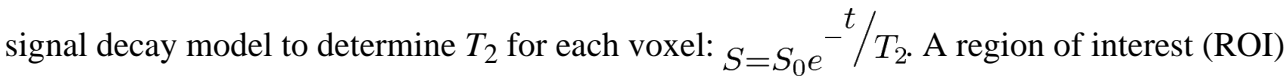
was manually drawn using Matlab (MathWorks, Inc, Natick, MA) for the first imaging time point and translated to the images from later echoes. The mean $T_{2}$ and standard deviation for each sample was calculated from all voxels within this ROI. Other imaging parameters included $T_{\mathrm{R}}=3$ seconds, field of view $=32 \mathrm{~mm} \times 32 \mathrm{~mm}$, data matrix $=128 \times 128$, tube thickness $=3 \mathrm{~mm}$, number of acquisitions $=4$ (total scan time $\sim 26$ minutes). For MRI of cells, $T_{2}$ signal decay was measured with $\mathrm{N}=32$ echoes with 8 millisecond echo spacing, $T_{\mathrm{R}}$ $=2500 \mathrm{~ms}$, field of view $=32 \mathrm{~mm} \times 32 \mathrm{~mm}$, data matrix $=128 \times 128(250$ micron in plane resolution), slice thickness $=1.5 \mathrm{~mm}$, number of acquisitions $=12$.

\section{Western blot analysis for GRP-R and AKT2}

GRP-R primary antibody was obtained from Abcam, Inc. (Cambridge, MA). AKT2 antibodies were purchased from Cell Signaling (Danvers, MA). Horseradish Peroxidase (HRP)-conjugated secondary antibodies against mouse and rabbit IgG were obtained from Santa Cruz Biotechnology, Inc. (Santa Cruz, CA). $\beta$-actin antibody and all other reagents were obtained from Sigma-Aldrich (St. Louis, MO). Western blotting was performed to examine protein levels and to evaluate the efficacy of transfection with CNT-siRNA in cells. Whole cell lysates were prepared by mixing cells with lysis buffer (Cell Signaling) containing $1 \mathrm{mM}$ PMSF and a protein inhibitor cocktail. Equivalent amounts of protein were separated on NOVEX NuPAGE 4-12\% Bis-Tris gels, transferred to polyvinylidene diflouride membranes, probed with primary antibodies (1:1000 dilution) overnight at $4{ }^{\circ} \mathrm{C}$, and followed by incubation with HRP-conjugated secondary antibody (1:5000 dilution) for $45 \mathrm{~min}$ at room temperature. Protein levels were visualized by an enhanced chemiluminescence substrate. Densitometry was performed using software Image $\mathbf{J}$ (National Institutes of Health).

\section{CNT-siRNA delivery into subcutaneous xenograft Tumors in vivo}

All experiments were approved by the Institutional Animal Care and Use Committee in accordance with guidelines issued by the National Institutes of Health. Male athymic nude mice (4-6 weeks old) were maintained as described ${ }^{49}$. BE(2)-C xenografts were established as previously described ${ }^{2,49}$. Briefly, BE(2)-C cells $\left(1 \times 10^{6}\right)$ in $100 \mu$ of HBSS were injected into the bilateral flanks using a 26 -gauge needle ( $n=3-5$ per group). CNT-siRNA 
treatments were performed from day 7 post tumor cell inoculation in mice. $50 \mu \mathrm{l}$ of the CNT-siRNA PBS solution with concentrations at $20 \mathrm{mg} / \mathrm{L}$ for CNTs and $1.7 \mu \mathrm{M}$ for siRNA was injected into each tumor. At sacrifice, tumors were harvested for analysis.

\section{In vivo bioluminescence Imaging}

In vivo bioluminescence imaging was performed as previously described. ${ }^{42}$ The substrate luciferin $(30 \mathrm{mg} / \mathrm{ml})$ was injected into the intraperitoneal cavity at a dose of $150 \mathrm{mg} / \mathrm{kg}$ body weight approximately $5 \mathrm{~min}$ before imaging. Mice were anesthetized with isoflurane/oxygen and placed on the imaging stage. Images were collected for 1 to $5 \mathrm{~s}$ using the Xenogen IVIS 200 bioluminescent imaging system (Xenogen Corp., Alameda, CA). Photons emitted from the tumor region were quantified using Living Image software (Xenogen Corp.).

\section{Immunohistochemistry}

Immunohistochemical staining was performed using DAKO EnVision+ System-HRP from Dako North America, Inc. (Carpinteria, CA). GRP-R primary antibody was purchased from Abcam, Inc. (Cambridge, MA). Human neuroblastoma xenografts were fixed in formalin overnight and embedded in paraffin wax. Tumor sections $(5 \mu \mathrm{m})$ were mounted on glass slides. Sections were deparaffinized with xylene, rehydrated with ethanol, antigen retrieval performed with $10 \mathrm{mM}$ sodium citrate buffer, and then blocked with blocking solution for $20 \mathrm{~min}$ at room temperature. Slides were incubated with GRP-R primary antibodies overnight at $4^{\circ} \mathrm{C}$. They were then washed with buffer three times for 5 min each and incubated with secondary antibodies for $30 \mathrm{~min}$ at the room temperature. Sections were developed with $\mathrm{DAB}$ reagent. The reaction was terminated by immersing slides in $\mathrm{dH}_{2} \mathrm{O}$ and sections were counterstained with hematoxylin. Slides were then dehydrated with ethanol and xylene. Coverslips were mounted and slides were left to dry. The IHC images were taken under microscope (Leica DMI6000 B). For mitosis detection, paraffin embedded sections were stained with anti-human phospho-histone H3 (Ser10) antibody followed by Alexa Fluor 568 Dye (Life Technologies, Grand Island, NY). DAPI (4',6-Diamidino-2Phenylindole, Dihydrochloride) was used for staining nucleus. Images were captured using a fluorescent microscope (Nikon Eclipse E600).

\section{Acknowledgments}

This work was supported by DK61470 from the National Institutes of Health (D.H.C.), Rally Foundation for Cancer Research (D.H.C.), ECCS-1055852, CBET-1067213, and EPS-1004083 from National Science Foundation (Y.X.), SCEEE Research Initiation Grant (Y.X.), and Vanderbilt Nicholas Hobbs Discovery Grant (Y.X.).

\section{References}

1. Bowen KA, Chung DH. Recent advances in neuroblastoma. Curr Opin Pediatr. 2009; 21(3):350-6. [PubMed: 19381091]

2. Qiao J, Kang J, Ishola TA, Rychahou PG, Evers BM, Chung DH. Gastrin-releasing peptide receptor silencing suppresses the tumorigenesis and metastatic potential of neuroblastoma. Proc Natl Acad Sci U S A. 2008; 105:12891-6. [PubMed: 18753628]

3. Akinc A, Zumbuehl A, Goldberg M, Leshchiner ES, Busini V, Hossain N, Bacallado SA, Nguyen DN, Fuller J, Alvarez R, Borodovsky A, Borland T, Constien R, de Fougerolles A, Dorkin JR, Narayanannair Jayaprakash K, Jayaraman M, John M, Koteliansky V, Manoharan M, Nechev L, Qin J, Racie T, Raitcheva D, Rajeev KG, Sah DW, Soutschek J, Toudjarska I, Vornlocher HP, 
Zimmermann TS, Langer R, Anderson DG. A combinatorial library of lipid-like materials for delivery of RNAi therapeutics. Nat Biotechnol. 2008; 26:561-9. [PubMed: 18438401]

4. Sood AK, Landen CN, Merritt WM, Mangala LS, Sanguino AM, Bucana C, Lu C, Lin YG, Han LY, Kamat AA, Schmandt R, Coleman RL, Gershenson DM, Lopez-Berestein G. Intraperitoneal delivery of liposomal siRNA for therapy of advanced ovarian cancer. Cancer Biol Ther. 2006; 5:1708-1713. [PubMed: 17106249]

5. Huang L, Li SD, Chono S. Efficient oncogene silencing and metastasis inhibition via systemic delivery of siRNA. Mol Ther. 2008; 16:942-946. [PubMed: 18388916]

6. Minko T, Patil ML, Zhang M. Multifunctional Triblock Nanocarrier (PAMAM-PEG-PLL) for the Efficient Intracellular siRNA Delivery and Gene Silencing. Acs Nano. 2011; 5:1877-1887. [PubMed: 21322531]

7. Moore A, Medarova Z, Pham W, Farrar C, Petkova V. In vivo imaging of siRNA delivery and silencing in tumors. Nat Med. 2007; 13:372-377. [PubMed: 17322898]

8. Nie S, Yezhelyev MV, Qi LF, O'Regan RM, Gao XH. Proton-sponge coated quantum dots for siRNA delivery and intracellular imaging. J Am Chem Soc. 2008; 130:9006-9012. [PubMed: 18570415]

9. Bhatia S, Agrawal A, Min DH, Singh N, Zhu HH, Birjiniuk A, von Maltzahn G, Harris TJ, Xing DY, Woolfenden SD, Sharp PA, Charest A. Functional Delivery of siRNA in Mice Using Dendriworms. Acs Nano. 2009; 3:2495-2504. [PubMed: 19673534]

10. Liu Z, Tabakman S, Welsher K, Dai HJ. Carbon Nanotubes in Biology and Medicine: In vitro and in vivo Detection, Imaging and Drug Delivery. Nano Res. 2009; 2:85-120. [PubMed: 20174481]

11. Liu Z, Tabakman SM, Chen Z, Dai HJ. Preparation of carbon nanotube bioconjugates for biomedical applications. Nat Protoc. 2009; 4:1372-1382. [PubMed: 19730421]

12. Star A, Tu E, Niemann J, Gabriel JCP, Joiner CS, Valcke C. Label-free detection of DNA hybridization using carbon nanotube network field-effect transistors. P Natl Acad Sci USA. 2006; 103:921-926.

13. Zheng M, Jagota A, Strano MS, Santos AP, Barone P, Chou SG, Diner BA, Dresselhaus MS, McLean RS, Onoa GB, Samsonidze GG, Semke ED, Usrey M, Walls DJ. Structure-based carbon nanotube sorting by sequence-dependent DNA assembly. Science. 2003; 302:1545-1548. [PubMed: 14645843]

14. Tu XM, Manohar S, Jagota A, Zheng M. DNA sequence motifs for structure-specific recognition and separation of carbon nanotubes. Nature. 2009; 460:250-253. [PubMed: 19587767]

15. Johnson RR, Johnson AT, Klein ML. Probing the structure of DNA-carbon nanotube hybrids with molecular dynamics. Nano Letters. 2008; 8:69-75. [PubMed: 18069867]

16. Bartholomeusz G, Cherukuri P, Kingston J, Cognet L, Lemos R, Leeuw TK, Gumbiner-Russo L, Weisman RB, Powis G. In Vivo Therapeutic Silencing of Hypoxia-Inducible Factor 1 Alpha (HIF-1 alpha) Using Single-Walled Carbon Nanotubes Noncovalently Coated with siRNA. Nano Res. 2009; 2:279-291. [PubMed: 20052401]

17. Yang R, Yang X, Zhang Z, Zhang Y, Wang S, Cai Z, Jia Y, Ma Y, Zheng C, Lu Y, Roden R, Chen Y. Single-walled carbon nanotubes-mediated in vivo and in vitro delivery of siRNA into antigenpresenting cells. Gene Ther. 2006; 13:1714-1723. [PubMed: 16838032]

18. Kam NWS, Liu Z, Dai HJ. Functionalization of carbon nanotubes via cleavable disulfide bonds for efficient intracellular delivery of siRNA and potent gene silencing. J Am Chem Soc. 2005; 127:12492-12493. [PubMed: 16144388]

19. Lanner JT, Bruton JD, Assefaw-Redda Y, Andronache Z, Zhang SJ, Severa D, Zhang ZB, Melzer W, Zhang SL, Katz A, Westerblad H. Knockdown of TRPC3 with siRNA coupled to carbon nanotubes results in decreased insulin-mediated glucose uptake in adult skeletal muscle cells. Faseb J. 2009; 23:1728-1738. [PubMed: 19141536]

20. Zhang ZH, Yang XY, Zhang Y, Zeng B, Wang ZJ, Zhu TH, Roden RBS, Chen YS, Yang RC. Delivery of telomerase reverse transcriptase small interfering RNA in complex with positively charged single-walled carbon nanotubes suppresses tumor growth. Clin Cancer Res. 2006; 12:4933-4939. [PubMed: 16914582] 
21. Wang XH, Ren JS, Qu XG. Targeted RNA interference of cyclin A(2) mediated by functionalized single-walled carbon nanotubes induces proliferation arrest and apoptosis in chronic myelogenous leukemia K562 cells. Chemmedchem. 2008; 3:940-945. [PubMed: 18286553]

22. Krajcik R, Jung A, Hirsch A, Neuhuber W, Zolk O. Functionalization of carbon nanotubes enables non-covalent binding and intracellular delivery of small interfering RNA for efficient knock-down of genes. Biochem Bioph Res Co. 2008; 369:595-602.

23. Liu Z, Winters M, Holodniy M, Dai HJ. siRNA delivery into human T cells and primary cells with carbon-nanotube transporters. Angew Chem Int Edit. 2007; 46:2023-2027.

24. Liu Z, Chen K, Davis C, Sherlock S, Cao QZ, Chen XY, Dai HJ. Drug delivery with carbon nanotubes for in vivo cancer treatment. Cancer Res. 2008; 68:6652-6660. [PubMed: 18701489]

25. Podesta JE, Al-Jamal KT, Herrero MA, Tian BW, Ali-Boucetta H, Hegde V, Bianco A, Prato M, Kostarelos K. Antitumor Activity and Prolonged Survival by Carbon-Nanotube-Mediated Therapeutic siRNA Silencing in a Human Lung Xenograft Model. Small. 2009; 5:1176-1185. [PubMed: 19306454]

26. Welsher K, Liu Z, Sherlock SP, Robinson JT, Chen Z, Daranciang D, Dai HJ. A route to brightly fluorescent carbon nanotubes for near-infrared imaging in mice. Nat Nanotechnol. 2009; 4:773780. [PubMed: 19893526]

27. Welsher K, Sherlock SP, Dai HJ. Deep-tissue anatomical imaging of mice using carbon nanotube fluorophores in the second near-infrared window. P Natl Acad Sci USA. 2011; 108:8943-8948.

28. Welsher K, Liu Z, Daranciang D, Dai H. Selective probing and imaging of cells with single walled carbon nanotubes as near-infrared fluorescent molecules. Nano Letters. 2008; 8:586-590.

[PubMed: 18197719]

29. Cherukuri P, Bachilo SM, Litovsky SH, Weisman RB. Near-infrared fluorescence microscopy of single-walled carbon nanotubes in phagocytic cells. J Am Chem Soc. 2004; 126:15638-15639. [PubMed: 15571374]

30. Cherukuri P, Gannon CJ, Leeuw TK, Schmidt HK, Smalley RE, Curley SA, Weisman RB. Mammalian pharmacokinetics of carbon nanotubes using intrinsic near-infrared fluorescence. $P$ Natl Acad Sci USA. 2006; 103:18882-18886.

31. Tsyboulski DA, Bachilo SM, Weisman RB. Versatile visualization of individual single-walled carbon nanotubes with near-infrared fluorescence microscopy. Nano Letters. 2005; 5:975-979. [PubMed: 15884905]

32. Choi JH, Nguyen FT, Barone PW, Heller DA, Moll AE, Patel D, Boppart SA, Strano MS. Multimodal biomedical imaging with asymmetric single-walled carbon nanotube/iron oxide nanoparticle complexes. Nano Letters. 2007; 7:861-867. [PubMed: 17335265]

33. Chen B, Zhang H, Zhai C, Du N, Sun C, Xue J, Yang D, Huang H, Zhang B, Xie Q. Carbon nanotube-based magnetic-fluorescent nanohybrids as highly efficient contrast agents for multimodal cellular imaging. J Mater Chem. 2010; 20:9895-9902.

34. Al Faraj A, Cieslar K, Lacroix G, Gaillard S, Canot-Soulas E, Cremillieux Y. In Vivo Imaging of Carbon Nanotube Biodistribution Using Magnetic Resonance Imaging. Nano Letters. 2009; 9:1023-1027. [PubMed: 19199447]

35. Al Faraj A, Fauvelle F, Luciani N, Lacroix G, Levy M, Crémillieux Y, Canet-Soulas E. In vivo biodistribution and biological impact of injected carbon nanotubes using magnetic resonance techniques. International Journal of Nanomedicine. 2011; 6:351-361. [PubMed: 21499425]

36. Ananta JS, Matson ML, Tang AM, Mandal T, Lin S, Wong K, Wong ST, Wilson LJ. SingleWalled Carbon Nanotube Materials as T2-Weighted MRI Contrast Agents. The Journal of Physical Chemistry C. 2009; 113:19369-19372.

37. Tucker-Schwartz JM, Hong T, Colvin DC, Xu YQ, Skala MC. Dual-modality photothermal optical coherence tomography and magnetic-resonance imaging of carbon nanotubes. Opt Lett. 2012; 37:872-874. [PubMed: 22378422]

38. Hong T, Lazarenko RM, Colvin DC, Flores RL, Zhang Q, Xu YQ. Effect of Competitive Surface Functionalization on Dual-Modality Fluorescence and Magnetic Resonance Imaging of SingleWalled Carbon Nanotubes. The Journal of Physical Chemistry C. 2012; 116:16319-16324. 
39. O'Connell MJ, Bachilo SM, Huffman CB, Moore VC, Strano MS, Haroz EH, Rialon KL, Boul PJ, Noon WH, Kittrell C, Ma JP, Hauge RH, Weisman RB, Smalley RE. Band gap fluorescence from individual single-walled carbon nanotubes. Science. 2002; 297:593-596. [PubMed: 12142535]

40. Moore VC, Strano MS, Haroz EH, Hauge RH, Smalley RE, Schmidt J, Talmon Y. Individually suspended single-walled carbon nanotubes in various surfactants. Nano Letters. 2003; 3:13791382.

41. Schipper ML, Nakayama-Ratchford N, Davis CR, Kam NWS, Chu P, Liu Z, Sun X, Dai H, Gambhir SS. A pilot toxicology study of single-walled carbon nanotubes in a small sample of mice. Nat Nanotechnol. 2008; 3:216-221. [PubMed: 18654506]

42. Zhang WS, Purchio AF, Chen K, Wu JM, Lu L, Coffee R, Contag PR, West DB. A transgenic mouse model with a luciferase reporter for studying in vivo transcriptional regulation of the human CYP3A4 gene. Drug Metab Dispos. 2003; 31:1054-1064. [PubMed: 12867495]

43. Hendzel MJ, Wei Y, Mancini MA, VanHooser A, Ranalli T, Brinkley BR, BazettJones DP, Allis CD. Mitosis-specific phosphorylation of histone $\mathrm{H} 3$ initiates primarily within pericentromeric heterochromatin during G2 and spreads in an ordered fashion coincident with mitotic chromosome condensation. Chromosoma. 1997; 106:348-360. [PubMed: 9362543]

44. Goto H, Tomono Y, Ajiro K, Kosako H, Fujita M, Sakurai M, Okawa K, Iwamatsu A, Okigaki T, Takahashi T, Inagaki M. Identification of a novel phosphorylation site on histone H3 coupled with mitotic chromosome condensation. J Biol Chem. 1999; 274:25543-25549. [PubMed: 10464286]

45. Preuss U, Landsberg G, Scheidtmann KH. Novel mitosis-specific phosphorylation of histone $\mathrm{H} 3$ at Thr11 mediated by Dlk/ZIP kinase. Nucleic Acids Res. 2003; 31:878-885. [PubMed: 12560483]

46. Patel O, Shulkes A, Baldwin GS. Gastrin-releasing peptide and cancer. Biochim Biophys Acta. 2006; 1766:23-41. [PubMed: 16490321]

47. Pei HD, Li L, Fridley BL, Jenkins GD, Kalari KR, Lingle W, Petersen G, Lou ZK, Wang LW. FKBP51 Affects Cancer Cell Response to Chemotherapy by Negatively Regulating Akt. Cancer Cell. 2009; 16:259-266. [PubMed: 19732725]

48. Tiemann K, Rossi JJ. RNAi-based therapeutics-current status, challenges and prospects. EMBO Mol Med. 2009; 1:142-51. [PubMed: 20049714]

49. Chung DH, Kang JH, Ishola TA, Baregamian N, Mourot JM, Rychahou PG, Evers BM. Bombesin induces angiogenesis and neuroblastoma growth. Cancer Lett. 2007; 253:273-281. [PubMed: 17383815] 
A
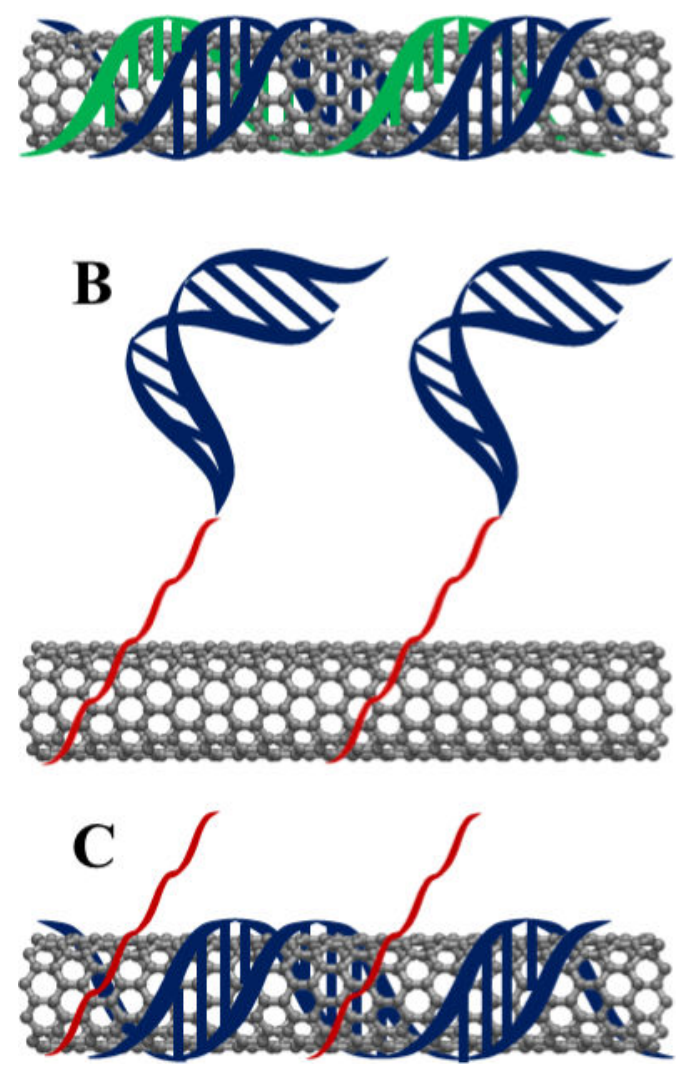

Figure 1.

Schematic diagrams of various CNT-siRNA. (A) ssDNA (green) was absorbed on the sidewall of a CNT to suspend the CNT in solution and siRNA oligonucleotides (blue) wrapped around the CNT through non-covalent aromatic interactions. (B) An amineterminated PEG-CNT was linked with siRNA via covalent bonds. (C) A PEG-CNT without any active functional group was conjugated to siRNA through non-covalent stacking interactions. Red lines represent PEGs. 


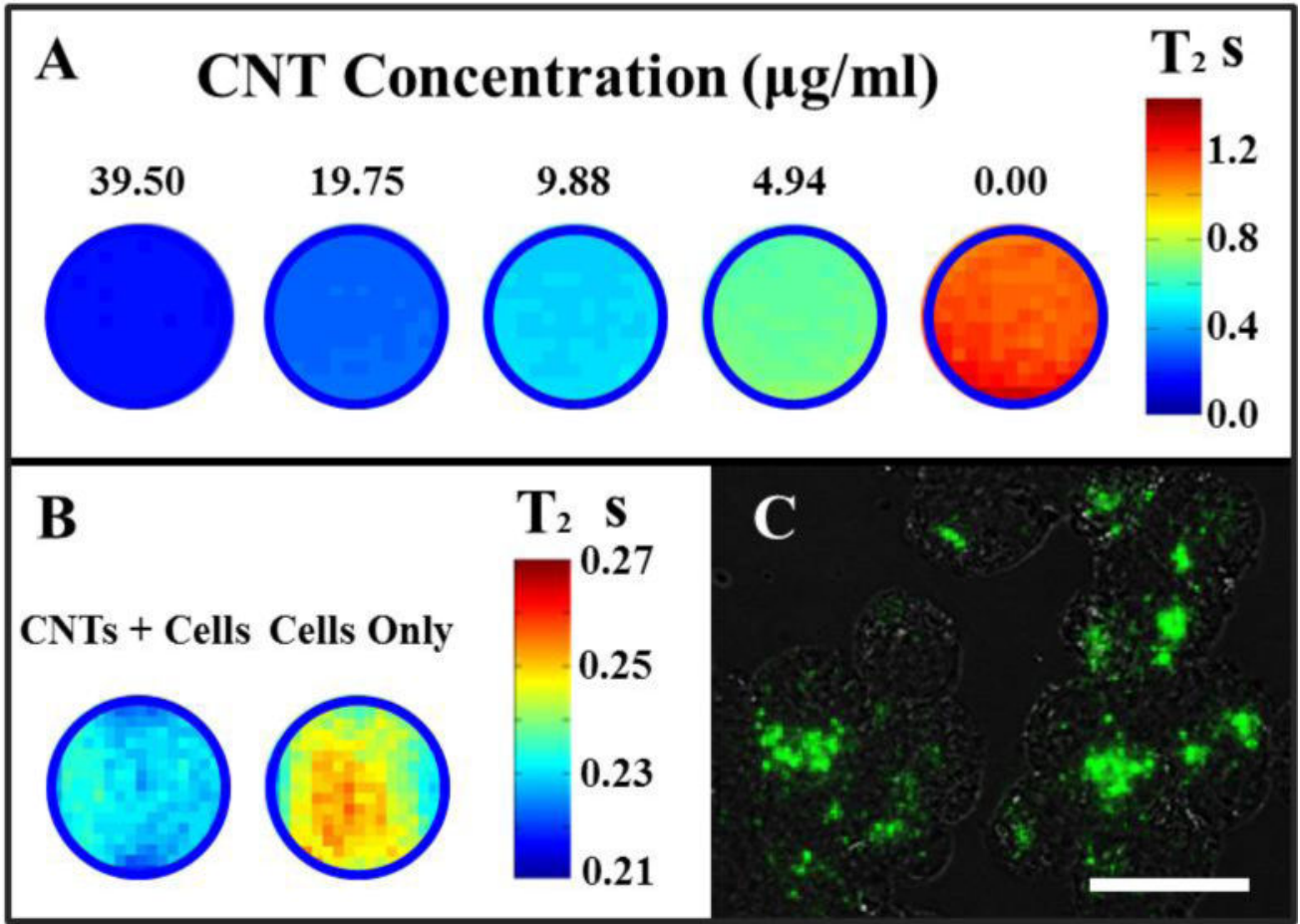

Figure 2.

Dual-modality imaging of CNTs. MRI $T_{2}$ maps of (A) PEG-CNT water suspensions with different concentration $(39.50,19.75,9.88,4.94$, and $0.00 \mu \mathrm{g} / \mathrm{ml})$ and (B) cells with (left) and without (right) CNT-siRNA treatments; (C) a fluorescence image of cells treated with CNT-siGRP-R overlaid by the corresponding optical image. The scale bar is $50 \mu \mathrm{m}$. 

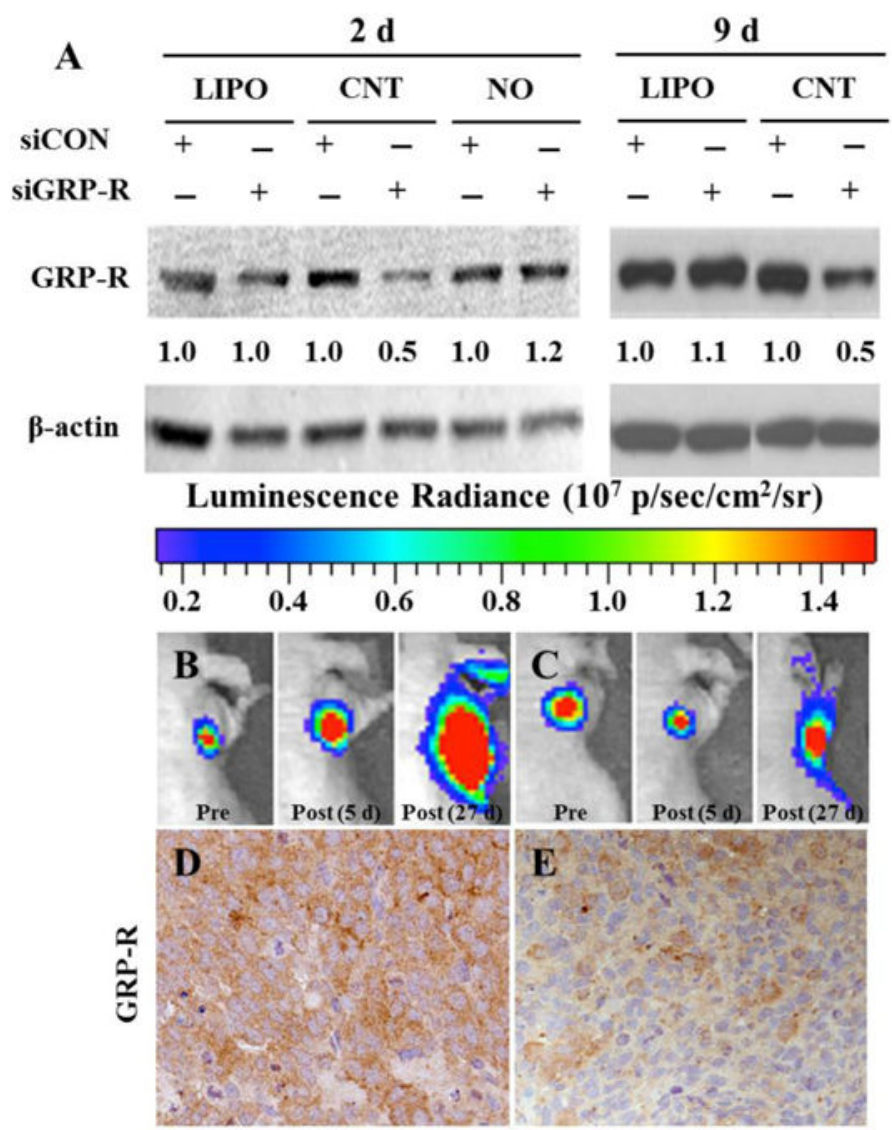

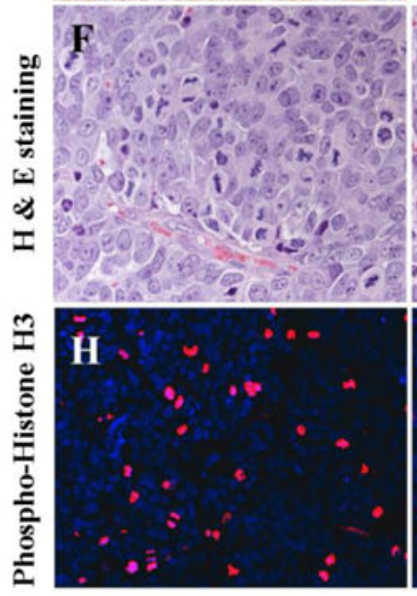

CNT-siCON

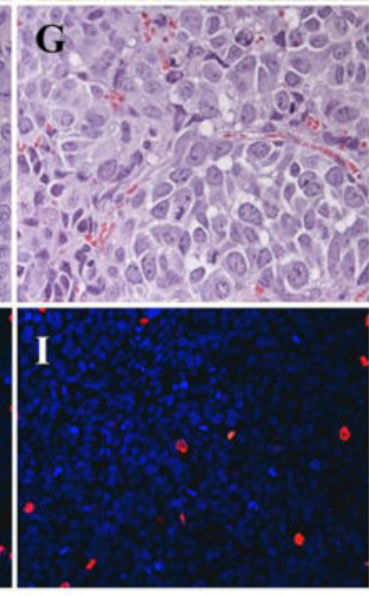

CNT-siGRP-R

Figure 3.

CNT-mediated GRP-R silencing in neuroblastoma in vitro and in vivo. (A) $\mathrm{BE}(2)-\mathrm{C}$ cells were treated with LIPO-siRNA, CNT-siRNA, and naked-siRNA for 2 and 9 days, respectively. Protein expression was detected by Western blotting. GRP-R expression was significantly silenced by CNT-siGRP-R, when compared to commercial transfection reagent LIPO and naked-siRNA. Relative levels of GRP-R were calculated by densitometry and listed below each band. $\beta$-actin was used as a loading control. (B, C) CNT-siRNA was injected locally into $\mathrm{BE}(2)-\mathrm{C}$ subcutaneous xenografts. Bioluminescence images were 
determined of mice treated with CNT-siCON or CNT-siGRP-R; CNT-siGRP-R significantly reduced the tumor size and inhibited the tumor growth. $(\mathrm{D}, \mathrm{E})$ Representative immunohistochemical staining of GRP-R in tumors treated with CNT-siCON or CNTsiGRP-R. The expression of target GRP-R (brown staining) was significantly decreased in CNT-siGRP-R treated tumor sections. (F, G) Representative H\&E-stained tumor sections from mice treated with CNT-siCON or CNT-siGRP-R. (H, I) Paraffin embedded sections were stained with anti-human phospho-Histone H3 (Ser10) antibody followed by Alexa Fluor 568 Dye (Red). DAPI (4',6-Diamidino-2-Phenylindole, Dihydrochloride, bue) was used for staining nucleus. CNT-siGRP-R treatments resulted in the loss of cell-cell adhesion (G) and a reduced number of mitotic cells (I), leading to decreased tumor cell proliferation and inhibition of tumor growth. 


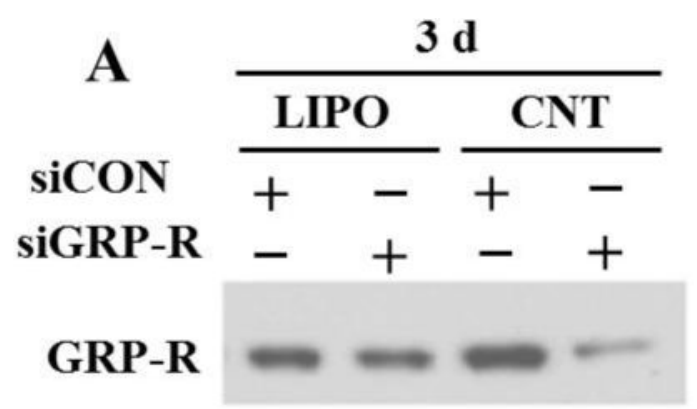

\section{$\begin{array}{llll}1.0 & 0.9 & 1.0 & 0.2\end{array}$}

AKT2

\section{$\beta$-actin}

B

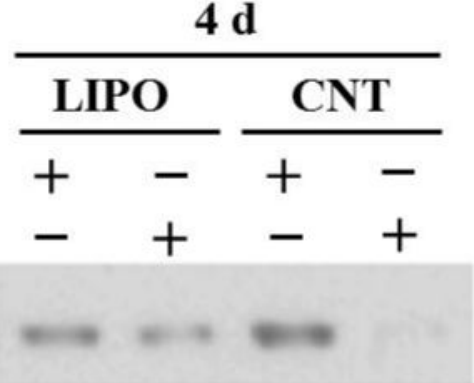

\section{$\begin{array}{llll}1.0 & 0.5 & 1.0 & 0.1\end{array}$}

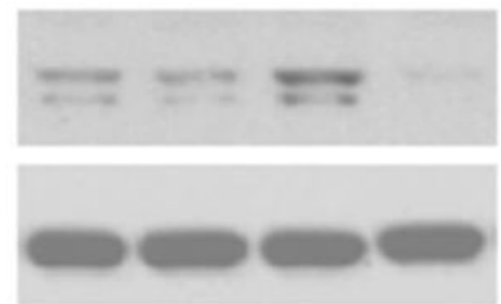

Figure 4.

High efficiency in other types of cancer cells. Human breast cancer MDA-MB-231 cells were transfected with CNT-siGRP-R or CNT-siCON for $72 \mathrm{~h}$ (A) and $96 \mathrm{~h}$ (B), respectively. Target GRP-R silencing was examined by Western blotting. LIPO-siGRP-R and LIPOsiCON were used as transfection control. CNT-siRNA distinctly silenced target GRP-R at both $72 \mathrm{~h}$ and $96 \mathrm{~h}$ time points. AKT2, a downstream target of GRP-R, was significantly decreased with CNT-siGRP-R. Relative levels of GRP-R were calculated by densitometry and listed below each band. $\beta$-actin was used as a loading control. 